\title{
Digitalised Legal Information: Towards a New Publication Model
}

\author{
Václav Janeček
}

\begin{abstract}
This chapter outlines some of the key developments regarding publication and communication of legal rules and standards (i.e. legal information) to show that dissemination of legal information is reliant on how we design the entire model of its publication. In doing so, it analyses paradigmatic models of publication as they appeared in the prehistorical, historical, and hyperhistorical stages of human evolution. These models demonstrate how legal information was delivered to its intended addressees, i.e. to those who were expected to obey the published laws. It also demonstrates that the progress regarding these publication models was driven by efficiency and sustainability considerations. The currently prevailing model of publication is, however, inefficient and unsustainable due to an unnecessary multiplication of intermediaries facilitating communication of legal information. This problem is even more apparent in the context of increasing digitalisation of legal information and emerging information and communication technologies (ICTs). The chapter argues that, in this light, it is appropriate to consider revising the entire publication model and not only some aspects of it. An addressee-centric publication model is outlined as a potential solution to the problem. The proposed model requires active delivery of a relevant subset of digitalised legal information to its intended addressee in a similar way as targeted online advertising. Unlike the existing research that promotes personalisation of law (personalised legal information), this chapter advocates personalisation of the publication model.
\end{abstract}

\section{Introduction}

Do you know how many new legal acts or regulations could have applied to you since last year? If you lived in the European Union (EU) in 2017, for example, it would be up to 131 entirely new directly applicable regulations and up to another 230 regulations amending the already existing EU law in force (EUR-Lex 2018). This means that, on average, approximately one new regulation was enacted each day last year. Suffice to add that apart from regulations there are many other types of legal sources that contain enforceable laws. Now, although these EU laws are freely available via the EUR-Lex online search engine, one has significant doubts about the size of the group out of the EU28's 511.8 million total population (Eurostat 2018) that has even the slightest idea about what these regulations regulate. As a lawyer myself, for instance, I know only a fraction of them.

A simple question arises then as to how addressees of the EU regulations can comply with such laws if they do not know their content or are not even aware of their existence in the first place. One option for them is to pay massive amounts of money to legal specialists and thereby gain sufficient legal knowledge to ensure necessary compliance with the laws. This setting, however, is inefficient and unsustainable because members of society are pushed towards desirable behaviour by lawyers holding

\author{
V. Janeček ( ( ) \\ Faculty of Law and St Edmund Hall, University of Oxford \\ Oxford, United Kingdom \\ e-mail: vaclav.janecek@law.ox.ac.uk \\ C. Öhman and D. Watson (eds.), The 2018 Yearbook of the Digital Ethics Lab \\ (C) Springer 2019 (forthcoming)
}


This is a pre-publication version-please cite with caution.

an imaginary carrot and stick, rather than being sustainably educated and informed about relevant legal rules and standards (i.e. legal information). EU regulations are only rarely discussed publicly-such as in the recent case of the General Data Protection Regulation (GDPR) ${ }^{1}$ - and our society thus remains legally incompetent, uninformed or even misinformed.

Had the lawyers and other legal specialists taken away the imaginary carrot and stick, most of us would soon be oblivious to the officially published legal information. This, in my view, is a problem because our society usually does not internalise newly published legal rules and standards and, therefore, does not mature legally or matures only very slowly. In this chapter, I argue that this does not need to be the case if we change the model of publication of digitalised legal information.

Imagine living in year 2096. Oxford University celebrates its $1000^{\text {th }}$ anniversary, the Digital Ethics Lab publishes the $79^{\text {th }}$ volume of its yearbook, and you-being part of a legally mature information society where peoples' expectations regarding legal rules almost perfectly match the existing regulations - enjoy living a decent life. In this not-too-distant future, a significant amount of digitalised legal information is directly implemented into software code and executed without human intervention (see e.g. a list of start-ups at Legal Geek 2018). The artificial intelligence (AI) based technological milieu largely eliminates human intermediaries to avoid inefficiencies, thus leaving the environment free of informational ballast that no human individual could comprehend or process. The remainder of legal information, i.e. non-self-executing information, is published under such a model that allows every relevant piece of legal information to be delivered to its addressee and to publicise and communicate this information repeatedly in appropriate contexts, thus efficiently and sustainably educating this addressee and, in turn, helping our society to mature legally.

Existing models of publication of legal information (at least in Europe) are yet far from the futuristic scenario as set out above, which gives us room for improvement. The current model of publication of EU law, for example, is a static one: the EU legal rules are produced in the EU legislative bodies and published in a static journal that is available online via the EUR-Lex search engine: the eOJ (electronic Official Journal of the European Union). EU citizens who want to find legal information freely must access actively this static journal themselves and perform a qualified search task. Alternatively, they can set up an alert system that will feed them with information about myriads of new EU legal documents. Therefore, although the EU regulations statically wait to be discovered and read by the law-abiding citizens, their quantity makes it unrealistic for the readers to actually get to know them. If the readers were to learn all the legal sources via this Web 1.0 interface, they would have no time left for doing anything else with their lives than reading said regulations (see Fig. 1 below). For non-specialists, searching for legal information thus inevitably becomes merely a heuristic task aimed at solving an individual problem. They are only interested in finding the relevant EU law when they deal with their own issues that they perceive as a legal problem. Accordingly, it is fair to assume that the EU citizens care nothing for the EU regulations at large, abstract knowledge of these regulations, and legal maturity of the society. The point is that, in a long run, such model is inefficient and unsustainable.

Fig. 1 Number of EU law Regulations enacted by year and type (data source: EUR-Lex 2018).

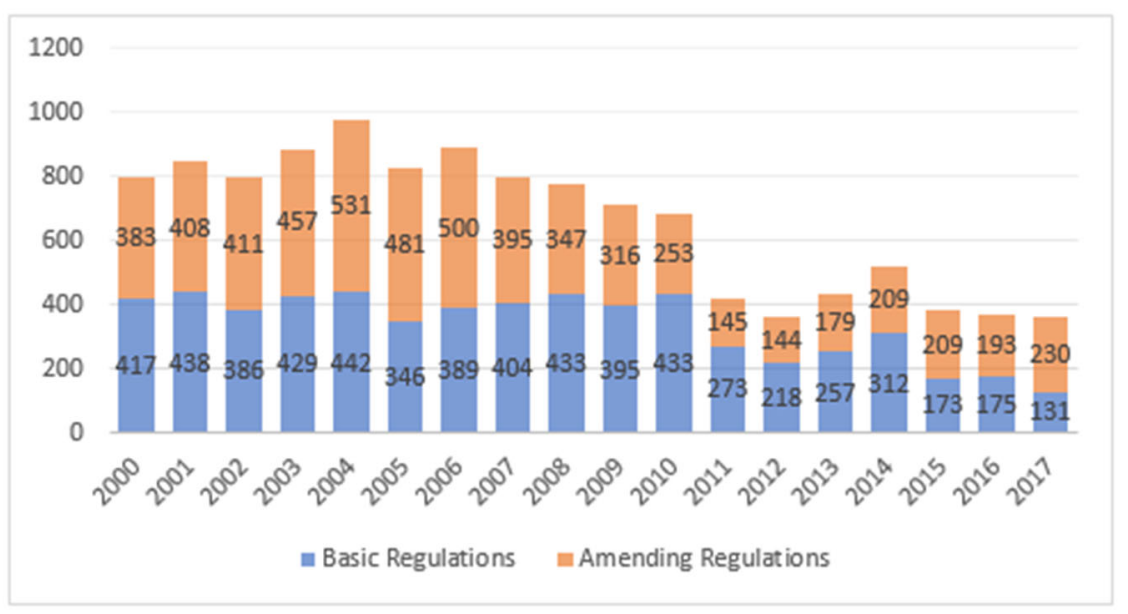

\footnotetext{
${ }^{1}$ Regulation (EU) 2016/679 of the European Parliament and of the Council of 27 April 2016 on the protection of natural persons with regard to the processing of personal data and on the free movement of such data, and repealing Directive 95/46/EC (General Data Protection Regulation) (OJ L 119/2016).
} 
This is a pre-publication version-please cite with caution.

In this chapter, I address the problem of publication models by exploring how these models evolved. In Section 2, I thus look at various stages of their past developments and use some iconic examples to demonstrate how models of publication of legal information are intertwined with the developments of information and communication technologies (ICTs) and how these models addressed the problems of inefficiency and unsustainability. Then I analyse common aspects of all publication models that need to be considered when discussing their development and adaptation to efficiency and sustainability challenges. These aspects are: a subject-matter of publication, a method of publication, a publisher, and an addressee. In Section 3, I explore the specifics of the digital challenge, namely digitalisation of legal information, emergence of $\mathrm{AI}$, and machine learning in relation to these four aspects of any publication model, and I canvass them against the efficiency and sustainability criteria. This allows me to outline some minimal features of a new model of publication of digitalised law in Section 4. I call it a model for digitalised hyperlaw. Finally, Section 5 stresses the originality of my findings in contrast with the existing research and shows directions for future work.

\section{The developing models of publication of legal information}

Looking back through the evolution of human societies, we can identify three distinct stages: prehistory, history, and hyperhistory (Floridi 2012). On this account, prehistory can be regarded as an era in which information is not recorded due to lack of recording methods. With Floridi we can thus describe prehistory simply as a stage in societal evolution before "the invention and development of information and communication technologies (ICTs)" (Floridi 2012: 129). The historical stage, then, "began with the invention of writing in the fourth millennium BC" (ibid: 129) which made it possible to record and transmit data over time and thereby create historical information. Finally, the hyperhistorical era marks a significant change in which societies use ICTs not only to record and transmit data but also to process them, which makes such hyperhistorical societies "vitally dependent on [... ICTs] and on information as a fundamental resource" (ibid: 130). It is important to mention that the developments in ICTs are not global. On one hand, some present societies live prehistorically, i.e. without ICTs, on the other hand the EU finds itself only at the onset of hyperhistory, because large parts of EU are still not reliant on ICTs processing of data and legal information.

In this context, recording, transmitting, and processing of data and legal information play a distinct role in each of these three societal stages and, as I will outline in this section, the emergence and developments of ICTs shaped significantly the models of publication of legal information. Accordingly, I will show that the developments of ICTs had a major impact on how societies legally organised themselves. In doing so, I will pick some paradigmatic models of publication from each of the three stages of societal evolution to demonstrate that the progress regarding publication models was driven by efficiency and sustainability considerations. We will see that each new model of publication and communication of legal information was expected to be more efficient and sustainable that the previous one.

\subsection{Prehistorical models}

Since long before people started recording legal information in writing, they used symbolic gestures and pronounced solemn words upon legally important transactions such as when concluding a contract or entering a marriage. They did it to mark the importance of the moment and to create at least an impression of the existing legal bond (Charpin 2010: ch 3). In such context, it was the witnesses in front of whom these gestures were performed and who thus testified the existence of such legal bond. In this sense, we can say that the witnesses acted as human recorders of relevant legal information, which made it slightly problematic in an environment where people could die easily and where life expectancy was very low. Legal information was thus only a short-term type of information and, on the top of it, it was not very transparent. Similarly, any superior societal authority, i.e. a powerful leader of a social group, who wanted to broadcast her or his own legal information could only rely on this inefficient model. So, for example, when someone got authoritatively punished for trespassing other's assets (e.g. for killing or stealing his life stock), the information about impermissibility of such trespass was only disseminated 
This is a pre-publication version-please cite with caution.

via stories and via vivid experiences of those involved in the execution of the (usually very harsh and painful) physical punishment.

In the context of such unwritten, short-term, and highly volatile system of recording, transmitting and processing of legal information, the rise and implementation of writing as a new technique presented an immense progress. Hence, written records of legal rules and legal information were soon demanded as the new standard. In fact, "a few jurists have believed that paragraphs from the Code of Hammurabi express the obligation imposed by the king to fix in written form contracts (relating to marriage, herding, or tenant farming), or risk having them invalidated" (ibid: 48). Not only did the invention of writing enable long-lasting access to legal information-e.g. by using clay tablets to record debts, transfers, and property claims in Old Babylonian kingdom (ibid: 49) — but it also facilitated a more structured and centralised model of publication of legal information. The sovereign could publish all the relevant legal information by a uniform method that was in principle independent of the mortal human "recorders" and "interpreters". One such method (to which I will turn in the next section) was to set legal rules in stone pillars that were erected in public places.

The dividing line between prehistory and history was never crystal clear because prehistory and history, "prelaw and law, or world of rite and oath on one hand, world of writing on the other" (ibid: 51) existed in parallel. These two eras were thus inextricably mixed, as for example Babylonian laws from the $20^{\text {th }}$ to $17^{\text {th }}$ century BC demonstrate (ibid: 51). Accordingly, to speak of a prehistorical model of publication of legal information, we need to focus on its ahistorical features. For the purposes of this chapter, therefore, the prehistorical model could be best described as a model of shared life experience, a model that could only accommodate and disseminate small amounts of legal information to a small number of people in a limited geographical area and for a short period of time. As such, the prehistorical model was generally inefficient and unsustainable, especially if we take a maturing society ruled by law as our benchmark.

\section{$2.2 \quad$ Historical models}

Some of the oldest written statues, and therefore evidence of some of the oldest historical models of publication of legal information are the famous Babylonian Code of Hammurabi (1754 BC) and Sumerian Code of Ur-Nammu (c. 2100-2050 BC). The Sumerian legal text is still considered the oldest surviving code on the planet (Kramer 1958: ch 7). What is typical of these codes is that they were carved into persistent materials such as stone and were stored and displayed at prominent places in the kingdom so that every subject to the king could come and see the binding law (i.e. key legal information) himself or herself. Practically the same model using physically immovable or only hardly moveable materials as a recorder of legal information was used in the Law of Twelve Desks (Leges Duodecim Tabularum) in the early Roman Republic (449 BC). Efficiency of this model was based on the fact that people went to public places where these laws were permanently displayed and where everyone could thus learn them. In comparison with the prelaw period, historical legal information could have been more easily preserved over generations and in principle, everyone could have gotten familiar with them. This did not apply only to authoritative rules but also to rules laid down in written contracts.

Still in the historical era, the advancements of ICTs - for instance the invention and implementation of transportable information carriers such as papyrus, parchment, or paper-made it easier to transform the static model of displayed information into a model where the promulgated laws could have been copied (rewritten) and disseminated across the territory in which they were supposed to be binding. Gradually, handwriting on lighter carriers became more widespread and made it possible to disseminate legal information widely. This could be seen as an advantage but also as a problem because legal information was communicated and disseminated rather chaotically, without a clear publication blueprint. The model was becoming less centralised and although common laws could have been transferred from one place to another simply by transporting the relevant legal document, the local laws could have evolved, and often also did evolve, in substantially different ways.

One way of dealing with this piecemeal publication model was to collect existing historical laws as they developed locally and provide a comprehensive overview of them. This was, for example, the case of Corpus Iuris Civlis which was compiled in the $6^{\text {th }}$ century AD subject to order by Eastern Roman Emperor Justinian I, and was then distributed across the Empire as authoritative evidence of existing 
This is a pre-publication version-please cite with caution.

laws. We can interpret this initiative as an attempt to re-gain control over legal information in the Emperor's territory, and also to monopolise the publication of such information by identifying an authoritative source of that information.

Another interesting model appeared in medieval England, shortly before one such formal source of legal information called Magna Carta Libertatum (1215 AD) was agreed to by King John of England. The English model addressed the problem of decentralisation not by collecting and redistributing common (yet locally distinct) laws, but by implementing a specific system of justice. The efficient dissemination of legal information was facilitated by travelling "itinerant" judges who dispersed justice according to common laws by going from town to town and hearing disputes of individuals. Paradigmatically, the model thus no longer required the royal subjects to travel to London to find out what the law was. The laws (figuratively speaking) travelled with the judges to the king's subordinates. In a sense, this model was very similar to the one of Eastern Roman Empire, except that it was not an a priori written collection of rules, but an a posteriori deciding judge who travelled around the country.

Even though it was the official authorities who were responsible for the "travels" of legal information via the court system and therefore could have maintained control over information dissemination, this model was bound to fail at keeping all published common laws comprehensible. This failure was due to both the increasing amount of judgments, as well as the practical a posteriori orientation of the publication model which was not focused on gathering comprehensive information about the common law system, but mainly on applying and disseminating particular legal information as widely as possible. No one could have, at the time, followed the work of every single judge across England, and therefore no one could have known how the common law was evolving. In practice thus, there was a shortage of access to the increasing body of common law. A provisional solution to this problem was then similar to the model of the Eastern Roman Empire: Sir William Blackstone $\left(18^{\text {th }}\right.$ century AD) collected the existing laws and gathered them into systematically structured volumes entitled Commentaries on the Laws of England. These volumes cleared the way for more principled and comprehensive recording and transmitting of laws. The missing a priori piece in the existing $a$ posteriori English publication model was thus found.

In the days of Blackstone, one very efficient form of ICT was already in place: the printing press. Historical estimates show that the overall

\begin{abstract}
European book production increased enormously [thanks to advancements in printing technologies] from somewhat more than 12,000 manuscripts per century (or 120 per year) from 500 to 700 , to more than one billion books published during the eighteenth century (the peak year in the period 500-1799 is 1790 , when more than 20 million copies were printed).
\end{abstract}

(Buringh, Van Zanden 2009: 417)

This made it possible to think anew about how to record and publicise legal information, even though books and printed manuscripts were still regarded as luxury goods (ibid: 440). The potential for developing a new publication model must have been obvious to anyone in the business of publishing.

The development of legal information and its publication models could have taken multiple routes, but a historical coincidence had it that, at the onset of the $19^{\text {th }}$ century, Europe witnessed an important codification movement resulting in the Code civil des Français (Code Napoléon), the Austrian Allgemeines bürgerliches Gesetzbuch (ABGB), etc. The preceding advancements in printing and overall increased literacy in Europe (Eisenstein 2012: ch 4) then supported the idea that laws could be written down in a compact form - a codification - to be distributed and read widely, much like the Bible. And although positive laws, unlike the Bible, proved to be constantly changing, this historical period made a significant step towards a uniform top-down model of printed publication which was very efficient and which still underpins many of the recent models of publication. The newly gained advantage was that if there were any amendments to the original legal text, the legislator could have only issued the amendment and the addressee could then physically attach this amending piece of information to the designated page in his or her own copy of the codification. Such model allowed for an unprecedentedly wide and efficient dissemination of legal information. The model was, on the face of it, also sustainable.

However, at the same time when the historical publication model started adhering to the idea of codifications, printing was still a low scale business. For instance, the Czech translation of the ABGB from 1812 was never printed in sufficient numbers so that Czech citizens could learn the civil code 
This is a pre-publication version-please cite with caution.

(ABGB) properly. Evidence suggests that printed translations of the ABGB were scarce and their copies quickly sold out (Janeček 2017: 52).

This was a problem only until mid- $19^{\text {th }}$ century, though, when a much more productive rotary printing press appeared. The rotary printing press made things easier but, at the same time, it spurred new troubles. On the one hand, the rotary printing technology in combination with the rise of industrial revolution steeply increased the capacity of printing houses in comparison with those using the outdated flat printing technology. As a result, legislators could now deliver printed legal information to virtually everyone in a relatively short time. The scarcity of printed legal information was no longer an issue. On the other hand, the invention of rotary printing press appeared too late to affect the already existing codification-based as well as printing-press-reliant publication model. It only changed one aspect of this model, namely the method or technology of publication.

One small step for publishers, but one giant leap for legislators. That is how we can describe the change that took place in the second half of the $19^{\text {th }}$ century. The new rotary printing technology, this relatively small advancement of publishers' capacity successfully defeated one important presumption that was present in every legislator's publication model until then. The axiomatic presumption was that laws cannot be changed instantly because communication technologies would not allow for efficient publication of such changes. Towards the end of $19^{\text {th }}$ century, however, this axiom was no longer valid. The development of ICTs (i.e. rotary printing technology) removed factual constraints on how frequently legislative changes and new rules can be made and, as we know from history, our law-making authorities took full advantage of this shift. This was the giant leap for legislators.

After this change, new rules and amendments are produced like never before, the rule-making increases and leads to what we may now call a hyperhistorical model of publication of legal information. In the upcoming models we must rely on ICTs not only to record and transmit legal information, but also process it, for otherwise we would not be able to navigate ourselves through this emerging "hyperlaw" and to manage the enormous amount of legal information.

\subsection{Hyperhistorical models}

To understand how hyperlaw has emerged, consider this outrageously simplified analogy. Imagine a Christmas tree. That is the initial body of law which was published by the rotary printing press regarding one specific area of law, for example the law of contract. Next, imagine that you start decorating the tree. The decorations represent all the new rules, amendments, and new cases in contract law which change the overall picture of this domain. Now, although everyone can buy such Christmas tree and although everyone can be equipped with the newest edition of the legal decorations, not everyone would know where to place these decorations on the tree. In the first instance, you could solve this problem by paying a specialist who will decorate the tree on your behalf, so that you can still see it as an intelligible source of legal information - as a nice Christmas tree. Had there been only one Christmas tree for every household, this solution could be, at least in theory, sustainable. But apart from the contract law pine tree, you would also need to have a tort law spruce tree, a criminal law fir tree, and so on. It is thus only feasible for a specialist to keep all the trees properly decorated. That is the existing model. It only allows the addressees of legal rules to come and see the tree for some ridiculously high fee that they pay to a specialist.

At this stage, complex legal information - the full array of Christmas trees-is privatised and de facto not freely accessible. A further problem is that once you create a market in Christmas decorations, you also incentivise production of new decoration sets, and the trees then start getting bigger and bigger. The growing piles of new decorations will eventually turn the Christmas tree arboretum into a messy jungle with no clear boundaries. At that point, what you get for your viewing ticket is anything but a series of "maybes" and unclear interpretations of the smudged images of the presumed body of law. Obviously, such model is not only inefficient and unsustainable, but also extremely costly. To repair this unappealing picture, lawyers first came up with a more specialist education of the professional decorators to train them to absorb the arboretum growth. Then they came up with creating legends, indexes and further guides to legal information in order to retain the disappearing picture of individual Christmas trees. Finally, we reached a point when we started outsourcing the processing of legal information (decorating of the trees) to new ICTs and their operators. This was the onset of hyperlaw 
This is a pre-publication version-please cite with caution.

and it started with the first computers, even before the dawn of the Internet (Bech-Capon et al. 2012; Leith 2016). Hyperlaw and hyperhistorical model thus arose in response to the unsustainable growth of legal information. Rather than to look at the jungle with awe, we started looking at it with new ICTs.

Currently, the hyperhistorical model looks roughly as follows. The formal sources of legal information are gathered by intermediaries controlling new ICTs. These ICTs are usually referred to as "legal information systems" (see Biasiotti, Faro 2011). ${ }^{1}$ They facilitate easier access to legal information by providing automated search engines and providing computing power that vastly outperforms humans in decorating the imaginary Christmas trees. This model makes it feasible to keep track of published legal information, but it demands everyone to go actively to the ICT-run database, just like people had to go to public places in the Sumer empire to see the legal engravings in stone pillars. The efficiency and sustainability of the hyperhistorical model is also undermined by the fact that most of existing legal information systems are not freely accessible.

\subsection{Four aspects of any publication model}

We have seen that changes to the models of publication of legal information correlated with changes to the ICTs, and that these changes seemed to respond to the problems of efficiency and sustainability of the models of publication. Perhaps there is even a causal link between the said issues. Here it suffices to say that such causation would not be unidirectional in a sense that the changing ICTs or the efficiency and sustainability problems would cause the changes to the models of publication. Instead, the causal link goes both ways. The examples show that ICTs can both cause and solve efficiency and sustainability problems, and that a new model can also eventually lead to these problems. To unfold these issues, it is useful to divide conceptually any publication model into minor parts and to show how these parts relate to ICTs and problems of efficiency and sustainability.

Looking at the three types of model (prehistorical, historical, and hyperhistorical), we can say that each publication model must entail four aspects: a subject-matter of publication; a method of publication; a publisher of legal information; and an addressee of published legal information. In this fourfold classification, the invention of the printing press, much like the invention of writing, internet, and other ICTs is best described in terms of a publication method. In themselves, these ICTs tell us little about what, by whom, and to whom legal information is published in a given model. A publication model, in contrast, represents a holistic description of a system in relation to which we can better assess efficiency and sustainability of such model. Take for instance the Sumerian method of erecting massive stone blocks with the code engraved on it. Such method may and may not be considered efficient and sustainable only when considered in relation to remaining aspects of a model.

\section{The digital challenge, AI, and machine learning}

Most recent developments in ICTs present "a digital challenge". This includes digitalisation of legal information, the emergence of the so-called intelligent ICTs popularly referred to as AI, and the increasing implementation of machine learning algorithms in processing of (but not only of) legal information. The digital challenge now poses a big obstacle to the existing model of publication. At the same time, it poses an opportunity for a significant improvement. Today's ICTs allow us to do things and process information in a way that was not only impossible but also unthinkable a decade ago. The next big question is thus how the existing publication models could accommodate these new ICTs.

It seems to me that there are two major alternatives how we may address the digital challenge and how we may use these new "smart" ICTs. On the one hand, it could result in implementing better methods of publication within the existing "Christmas tree" model as outlined in Section 2.3. On the other hand, it could be seen as a challenge to the model as such. Let us therefore consider implications of the digital challenge in relation to all four aspects of any publication model (a subject-matter; a

\footnotetext{
${ }^{1}$ See Free Access to Law Movement. http://www.fatlm.org/ [https://perma.cc/3SMF-KZGH]; World Legal Information Institute. http://www.worldlii.org/ [https://perma.cc/322G-BMSD]; Legal Information Management journal-ISSN: 14726696 (Print), 1741-2021 (Online).
} 
This is a pre-publication version-please cite with caution.

method; a publisher; an addressee) to see whether the second variant could be justified in the light of the challenge.

\subsection{A subject-matter}

The most apparent implication of the digital challenge for the subject-matter of legal information is twofold. For one, legal information has been digitised and practically all positive laws in Europe now formally (also) exist in some form of a digital sequence. This does not in itself alter the substance of such information, i.e. its meaning. Yet the machine-readable digital form of legal data further magnifies our dependence on ICTs, for without ICTs we would no longer understand the digital data set. And although the subject-matter still coexists in digital (machine-readable) and analogue (human-readable) from, the digital challenge slowly puts more weight on the digital form of legal information. For instance, if a text of a statute is amended by the legislator, then the consolidated full-text of the amended statute is typically produced only in the digital form. Derivatively, the ICTs extract information from the digital data representing the amended statute so that we can read it as a full-text. The first implication thus relates to the formal expression of legal information. A danger in this regard is that digital data will overtake the role of a primary source of legal information, rather than secondary formal expression of such information. Such scenario is not unlikely to happen given that expert legal discourse often confuses data with information (Janeček 2018).

The second implication applies to the substance of legal information. The digital challenge affects "what" legal information is recorded, transmitted, and processed. On one hand, there are new ICTs for existing laws, such as the emerging phenomenon of smart contracts. Smart contracts are designed to process contractual obligations without human intervention, i.e. automatically (Cuccuru 2017). This eliminates several steps in the process of application of contractual law, which is cost efficient. Yet it also black-boxes legal information that are processed during those steps. The contractual parties no longer need to understand the rules and legal information that are applied by the smart contract. They merely see the result - usually an information about legal sanction (e.g. contractual penalty or tax deduction) that was automatically applied by the smart contract. As a result, this could undermine the role of primary legal information (rules on how one should act) and stress the role of secondary sanctions, thereby eliminating certain types of legal information from the discourse and from publication. Whether this is a good thing is something that is still to be explored, albeit not in this chapter.

On the other hand, we may also think of the digital challenge as giving rise to substantive laws for the new ICTs. In other words, we can contrast ICTs for law with law for ICTs (cf Ruhl 2018). Debates on laws for new ICTs, AI, and for machine learning algorithms are now thriving in Europe and beyond (e.g. Lepri et al 2017; Wachter, Mittelstadt, Floridi 2017). It thus proves important to consider, inter alia, to whom these regulations should be addressed and whether, or to what extent, such information should be seen as part of some unitary legal information category. I will return to this issue in section 3.4 , but here it is important to mention that new regulations for new ICTs need not to be instructional in the sense as a rule not to kill people is instructional. Instead, they can take the shape of organisational norms or standards just like the EU regulation of electronic signatures (signatures that fulfil certain requirements will gain the same level of legal protection in all EU Member States). ${ }^{2}$ If that is the case, then efficiency of publication of such information does not need to be measured by how many addressees know about such standard, but also by how many new ICTs comply with such standard. In other words, in light of the digital challenge, the entire publication model could be evaluated against the direct implementation of legal information.

\footnotetext{
2 Regulation (EU) No 910/2014 of the European Parliament and of the Council of 23 July 2014 on electronic identification and trust services for electronic transactions in the internal market and repealing Directive 1999/93/EC (OJ L 257/2014).
} 
This is a pre-publication version-please cite with caution.

\subsection{A method}

As regards the method of publication of legal information, the emerging technological advancements put forward new opportunities for how to record, transmit, and process legal information, as well as how to publish it (see Bech-Capon et al 2012; Leith 2016). The vast majority of implementations of new ICTs try to enhance the existing models by employing the computational power of ICTs and therefore processing of more data and legal information. This means that most of new solutions, as far as one can tell by literature review or by looking at start-ups in law \& technology (Legal Geek 2018), merely revise the method of recording, transmitting, and processing of legal information, leaving the three remaining elements unchallenged. But this does not have to be the case.

New ICTs also open up possibilities to process legal information differently at the pre-publication stage. The most distinctive proposals in this regard suggest personalisation of legal information, i.e. bespoke tailoring of the subject-matter of publication (e.g. Casey, Niblett 2016; Ben-Shahar, Porat 2016; Porat, Strahilevitz 2014). This would mean creating of personalised rules and standards. For example, the current law can hold you liable if you cause damage to others by acting negligently. The negligence standard is now expressed in generic terms of "what would have a reasonable person done had this person been in your situation". If this legal information was personalised (e.g. by analysing big data sets containing information about yourself and by comparing them with information about past wrongdoers who were already held liable for breaching the negligence rule), it could be possible to create a more refined negligence standard for each individual. This processing of legal information could take place before another type of ICT disseminates it.

But there are other routes which one may take with regard to implementation of new ICTs in methods of publication of legal information. For instance, ICTs may be used to disseminate legal information more efficiently by lowering the importance of central databases (core nodes with legal information) and by letting the data run across the ICT-infrastructures more actively to reach its intended addressees. Methodically, ICTs can thus change the entire picture of publication models and we need to carefully consider at which stage of the existing model it could do so for the greatest benefit and with minimal harm. Alternatively, we should consider how to adapt the existing model to make full use of new ICTs. This, again, will need to be assessed against efficiency and sustainability of such model.

\subsection{A publisher}

The digital challenge then inevitably raises questions regarding the publisher of legal information, because although the original author of the information could be an official authority, the publishers of such information are often private entities or black-boxed mechanisms. The pressing issue in this context is whether-once we start relying on new ICTs in respect of not only recording and transmitting but also processing of legal information-published information will remain authentic and not misinterpreted by such processes. The optimal model should thus carefully consider how such risks might be internalised, e.g. by not contracting out the publication responsibility to external entities which are driven by economic rather than efficiency or sustainability goals.

Another challenge is that multiplication of publishers (whoever they are) might lead to decentralised, divergent and, at the end of the day, incomprehensive publication practice. We know that this happened in the past and nothing suggests that the present era would be immune to such issues. The digital challenge, therefore, justifies that we revise the overall parameters of the publication model.

\subsection{An addressee}

With new ICTs and their implementation in publication models, it is finally important to ask to whom legal information shall be delivered and thus also to whom it shall be published. Publication of legal information to the public at large (i.e. just making such information in principle publicly available) is no longer efficient and sustainable, as I tried to show in the introduction to this chapter. The problem is that the existing model is designed mainly to suit the needs of legal specialists. It is them to whom the law-making authority often speaks in the first instance, or at least that is how the model is designed. 
This is a pre-publication version-please cite with caution.

And although there are initiatives trying to facilitate free access to law around the globe, such as the Free Access to Law Movement, without sufficient specialist knowledge, it is hard for anyone to find a way through the piles of digitised online accessible legal documents.

The main addressees of these legal information systems thus are legal specialists and ordinary citizens usually get to know about existing rules via different channels such as TV, radio, school education, or by unpleasant encounters with law enforcing authorities. That, I think, is not an optimal situation since the addressees of legal information are not the same as addressees of publications of such information. There is an apparent and alarming discrepancy between those to whom the rules are published and those who shall obey them.

It seems to me, though, that the emerging ICTs now give us room to revise this model and to bring publication of legal norms closer to its addressees, e.g. by displaying relevant information in virtual locations where they should be applicable, by displaying them only when they should be applicable, or by displaying them only to those whom should apply them. Eventually, then, some legal information such as the organisational norms and standards (see Section 3.1) could be directly implemented in the ICTs which should comply with such standards.

\section{A new model for digitalised hyperlaw}

The digital challenge compels us to re-think and, if necessary, also to re-design the current publication model in order to facilitate more efficient and sustainable flow of legal information that would reach more addressees. Modern technologies and digitalisation of legal sources also allow us to make these sources and rules truly public again. Looking back through my brief discussion of all four aspects of any publication model, it shall now be clear that the digital revolution and emergence of hyperlaw alongside new ICTs could spur such novel proposals. The discussion also revealed that any model should not be evaluated against its isolated aspects. By contrast, if a new model is to be efficient in publishing and communicating legal information and delivering it to its true addressees, i.e. to those who are expected to comply with given legal rules or standards, then our assessment of its design must jointly consider all four aspects: the subject-matter of publication, the method of publication, the publisher, and the addressee.

The basic idea behind the existing model is that people - as addresses of the relevant legal information - have the responsibility to know the laws and thus also have a duty to act accordingly, i.e. search for the information. If legal information will be delivered efficiently to its addressees in time, i.e. before they are expected to follow them, we could once again substantiate the idea that one's own ignoration of laws is not an excuse. But that would probably demand us to shift the burden of publication duties towards the state or public authorities, rather than to let the addressees to search actively for such information.

To keep such model not only efficient but also sustainable, it seems to me that one would need to decrease the total number of published legal information because a single person cannot read all the laws in her entire life and because most of these laws are simply not relevant to her. That, however, does not need to imply that legislation and case law, as we know it nowadays, needs to be reduced in their quantity. The problem could be dealt with at a different level. Let us remind ourselves for a moment of the example that I used in the introduction to this chapter. The image there was a personalised model of publication where you, as an addressee of a legal norm would be targeted and informed about such rule in time much in the same way as you now receive personalised advertisements. Note that this model does not require personalisation (and therefore multiplication) of legal information. On this account, legal systems could retain much of their features; only the rules and standards would be published and disseminated differently.

Moreover, it is possible to imagine that some standards and perhaps also some rules could be disseminated and implemented directly into new technologies. Such legal information would then become embedded in the informational hyperhistorical environment which we now create. As a result, a new model of publication of legal information could ensure that relevant legal information will be known and present in those locations where they should be applied. As a mature information society, we could simply eliminate some intermediaries (e.g. the intermediating legal information systems and their operators) and we could embed some regulations directly into the code of ICTs that process other 
This is a pre-publication version-please cite with caution.

legal information. This could, in effect, significantly lower the amount of information that human addressees need to process themselves.

Such envisaged model could be both efficient and sustainable, but without further research, it can bring additional ethical issues. On one hand, by returning legal information into the physical environment (by direct implementation), the model could bridge the digital divide between those who have access to ICTs and new technologies and those who do not have such access. On the other hand, such full shift to hyperlaw could make us fully reliant on ICTs and lead to, for instance, our loosing of many specialist skills and knowledge, or to diminishing responsibility of human agents (Yang et al 2018: 11). One response to such ethical challenge could be to implement the new hyperlaw model of publication on top of the existing framework, rather than to see it as its replacement. This, however, could prove costly and unsustainable in the long run.

\section{Conclusion}

I hope to have persuaded the reader that the digital challenge gives us reasons to revise the existing models of publication of legal information. The current models are inefficient and unsustainable mainly because the existing publication methods are designed to serve legal professionals and not the ultimate addressees of legal information. This creates the unnecessary multiplication of intermediaries facilitating communication of legal information between the original law-making authority and the intended addressee. The problem thus is that publication models do not serve those who are expected to know the laws and comply with them. A new model should bridge this gap by bringing our attention back to the ultimate addressee of legal information.

Given the developments in ICTs, it is now possible to let the digital data reach its addressees and convey the relevant bits of legal information to them. In contrast with the existing models, it no longer seems necessary that people would search actively for legal information themselves. Instead, data conveying legal information may search for people - for the potential addressees. In addition, the developing ICTs make it possible, at least in theory, directly to implement some legal information by delivering it to an ICT that is expected to be compliant with the laws itself. The regulated technology could thus be a direct addressee of some legal information. Such solution could be referred to as an addressee-centric publication model. In contrast with existing research that promotes personalisation of the published legal content (personalised legal information), this proposal advocates personalisation of the entire publication model.

The purpose of this chapter was, however, only to outline the addressee-centric model as the potential next step in the evolution of publication models. The overall design of such (or any other new) publication model needs to be explored in future research should we want to take full advantage of the digital challenge, and should we want to make our publication model efficient and sustainable once again. In this regard, I tried to show what can be learned from the past, namely that publication of legal information is better thought of as part of a holistic model that contributes to "legal" maturing of our society. Besides, I showed that it could be beneficial to separate different aspects of any publication model (a subject-matter; a method; a publisher; an addressee) to see better how efficient and sustainable such model could be when we combine these aspects. A solid grounding for future work in this area can be found around international initiatives such as the Free Access to Law Movement, International Association for AI and Law, or Legal Geek, albeit they (so far) only focus on individual aspects of the publication model. 
This is a pre-publication version-please cite with caution.

\section{References}

1. Bench-Capon, T., et al. (2012). A history of AI and Law in 50 papers: 25 years of the international conference on AI and Law. Artificial Intelligence and Law, 20(3), 215-319. doi:10.1007/s10506012-9131-x.

2. Ben-Shahar, O., \& Porat, A. (2016). Personalizing negligence law. New York University Law Review, 91(3),627-688.

3. Biasiotti, M.A., \& Faro, S. (2011). From Information to Knowledge: Online Access to Legal Information-Methodologies, Trends and Perspectives. Amsterdam: IOS Press.

4. Buringh, E., \& Van Zanden, J.L. (2009). Charting the "Rise of the West": Manuscripts and Printed Books in Europe, a Long-Term Perspective from the Sixth through Eighteenth Centuries. The Journal of Economic History, 69(2), 409-445. doi:10.1017/S0022050709000837.

5. Casey, A.J., \& Niblett, A. (2016). Self-Driving Laws. University of Toronto Law Journal, 66(4), 429-442. doi:10.3138/UTLJ.4006.

6. Charpin, D. (2010). Writing, Law, and Kingship in Old Babylonian Mesopotamia (trans: Todd, J.M.). Chicago: University of Chicago Press.

7. Cuccuru, P. (2017). Beyond bitcoin: an early overview on smart contracts. International Journal of Law and Information Technology, 25(3), 179-195. doi:10.1093/ijlit/eax003.

8. Eisenstein, E.L. (2012). The Printing Revolution in Early Modern Europe, 2nd edn. Cambridge: Cambridge University Press.

9. EUR-Lex (2018). Online statistics. http://eur-lex.europa.eu/statistics/legislative-actsstatistics.html [https://perma.cc/WF8Q-QSN6].

10. Eurostat (2018). Population as of 1 January. $\mathrm{http}: / /$ ec.europa.eu/eurostat/tgm/table.do?tab=table\&init=1\&language $=$ en $\& p c o d e=t p s 00001 \& \mathrm{plu}$ gin=1 [https://perma.cc/NN7P-F4CS].

11. Floridi, L. (2012). Hyperhistory and the Philosophy of Information Policies. Philosophy \& Technology, 25(2), 129-131. doi:10.1007/s13347-012-0077-4.

12. Janeček, V. (2018). Ownership of personal data in the Internet of Things. Computer Law \& Security Review, 34(5), 1039-1052. doi:10.1016/j.clsr.2018.04.007

13. Janeček, V. (2017). Kritika právni odpovědnosti. Prague: Wolters Kluwer.

14. Kramer, S.N. (1958). History begins at Sumer. London: Thames \& Hudson.

15. Legal Geek (2018). Start-up map. https://www.legalgeek.co/startup-map/ [https://perma.cc/HT35-C226].

16. Leith, P. (2016). The rise and fall of the legal expert system. International Review of Law, Computers \& Technology, 30(3), 94-106. doi:10.1080/13600869.2016.1232465.

17. Lepri, B., et al., (2017). Fair, Transparent, and Accountable Algorithmic Decision-making Processes. Philosophy \& Technology. https://doi.org/10.1007/s13347-017-0279-x.

18. Porat, A., \& Strahilevitz, L.J. (2014). Personalizing Default Rules and Disclosure with Big Data. Michigan Law Review, 112, 1417-1478.

19. Ruhl, J.B. (2018). Expanding the AI \& Law Matrix. In: Law 2050. https://law2050.com/2018/02/19/expanding-the-ai-law-matrix/ [https:/perma.cc/S32P-RT4F].

20. Wachter, S., Mittelstadt, B., Floridi, L. (2017). Transparent, Explainable, and Accountable AI for Robotics. Science Robotics, 2(6), 1-2. doi:10.1126/scirobotics.aan6080.

21. Yang, G.-Z., et al., (2018). The Grand Challenges of Science Robotics. Science Robotics, 3(14), 1-14. doi:10.1126/scirobotics.aar7650. 